\title{
Tension Free Transvajinal Tape Uygulaması Sonrası Mesh Erozyonu Nedenli Mesane Taşı Olgusu
}

\section{A Case of Bladder Stone Secondary to Mesh Erosion after Tension Free Transvajinal Tape Procedure}

Jule Eriç Horasanlı

${ }^{1}$ KTO Karatay Üniversitesi, Medicana Tıp Fakültesi Hastanesi, Konya, Türkiye

Geliş Tarihi/Received: 28 Haziran 2018 Kabul Tarihi/Accepted: 15 Kasım 2018

Yazışma Adresi: Jule Eriç Horasanlı, Necmettin Erbakan Üniversitesi Meram

Tıp Fakultesi Kadın Hastalıkları ve Doğum Anablim Dalı, Konya, Türkiye

e-posta: juleesen@gmail.com

ORCID

Jule Eriç Horasanlı

https://orcid.org/0000-0002-8738-7126

\begin{abstract}
Öz
Tension free transvajinal tape operasyonu kısa hospitalizasyon süresi ve uygulama kolaylığı nedeni ile stres üriner inkontinansta oldukça popüler hale gelmiştir. Stres inkontinas tedavisinde tension free transvajinal tape başarılı ve güvenli bir prosedür olmasına rağmen, çeşitli intraoperatif ve postoperatif komplikasyonlar gelişebilmektedir. Bu çalışmamızda, 7 yıl önce geçirdiği stres üriner inkontinans nedeniyle tension free vajinal tape ve pelvic organ prolapsusu nedeniyle kolporafi anterior operasyonu sonrası mesh erozyonuna bağlı mesane taşı gelişen ve başarılı bir şekilde tedavi edilen bir olguyu tanımladık.

Anahtar Kelimeler: Tension free transvajinal tape ope, stres üriner inkontinans, mesane taşı, mesh erozyonu, pelvic organ prolapsusu

\section{Abstract}

Tension free transvajinal tape operation has become popular in the treatment of stress urinary incontinence because of its short hospitalisation time and ease of application. Although tension free transvajinal tape is a successful and safe procedure in the treatment of stress urinary incontinence, several intraoperative and postoperative complications might be seen. In our study, we described a case of bladder stone that developed secondary to mesh erosion after tension free transvajinal tape operation for stress incontinence and reconstructive surgery (anterior colporrhaphy) for pelvic organ prolapse performed 7 years previously and who was successfully treated.
\end{abstract}

Keywords: Tension free transvajinal tape operation, urinary stress incontinence, bladder stone, mesh erosion, pelvic organ prolapse

\section{GíRiş}

Gerçek stres üriner inkontinans (SUi) öksürme, ıkınma ve egzersiz gibi intraabdominal basıncı artıran durumlar ile ortaya çıkan istemsiz idrar kaçırma durumudur (1). Ülkemizde yapılan bir çalışmada menopozda olmayan kadınlarda \%21,6, menopozda olanlarda ise \%50 oranında üriner inkontinans bildirilmiştir (2). Bu durumun tedavisinde kullanılabilen pelvik taban egzersizleri ve inkontinans pesserleri gibi konservatif yöntemler yetersiz kaldığında cerrahi işlemler gündeme gelmektedir. 1996'da Ulmsten ve ark. tarafından tanımlanan Tension free transvajinal tape (TVT) tekniği, lokal anestezi altında minimal diseksiyonla uygulanabilmesi ve cerrahi girişim süresinin kısa olması gibi nedenlerle stres üriner inkontinas cerrahi tedavisinde yaygın olarak kullanılmaktadır (3). Bu yöntemde orta üretra non absorbabl polypropylene tape ile kuvvetlendirilir, puboüretral ligament tekrar oluşturulur (De Lancey anatomik modeli) (3).

TVT operasyonu her ne kadar kısa hospitalizasyon süresi ve uygulama kolaylığı nedeni ile gerçek SUl'ta oldukça popüler hale gelmiş olsa da kanama, mesane ve diğer organ perforasyonu gibi intraoperatif komplikasyonlar gelişebilmektedir (4). Bu komplikasyonlar intraoperatif olarak tanınıp tedavisi yapılırsa geç komplikasyonlar azaltılabilir.

SUI'ın TVT yöntemi ile cerrahi düzeltilmesi sonrası postoperatif dönemde persistan idrar yapma güçlüğü, uzun süreli üriner retansiyon ve tam olmayan mesane boşalması gelişebilir (5). Daha nadir olarak vajinal duvarda mesh erozyonu, üretral erozyon gibi komplikasyonlar bildirilmiştir (6). İnkontinans cerrahisi sonrası mesane erozyonu ya da obstrüksiyona bağıı olarak mesane taşı gelişebilir. Postoperatif ağrıı idrar yapma ya da piyüri şikayeti olan hastalarda bu

Atıf yapmak için: Horasanlı JE. Tension Free Transvajinal Tape Uygulaması Sonrası Mesh Erozyonu Nedenli Mesane Taşı OIgusu. Selcuk Med J 2020;36(1): 59-61 
durumdan şüphelenilmelidir.

\section{OLGU}

Yaklaşık 7 yıl önce SUI nedeniyle TVT ve POP (Pelvik Organ Prolapsusu) nedeniyle kolporafi anterior operasyonu geçiren 65 yaşındaki hasta, son birkaç aydır olan idrar yaparken yanma bilateral yan ağrısı, suprapubik ağrı şikayeti ile başvurdu. Antibiyotik tedavisi ile geçmeyen bir üriner enfeksiyon yakınması mevcuttu. Yapılan jinekolojik muayenede vajende mesh erozyonuna rastlanmadı, fakat yaklaşık 1,5 $\mathrm{cm}$ 'lik bir alanda fibrotik bir doku izlendi. Hastaya tam idrar tetkiki yapıldı. 3-4 lökosit, 1-2 eritrosite rastlandı. C-reaktif protein (CRP) $1.29 \mathrm{mg} /$ litre olarak tespit edildi. Alt batın bilgisayarlı tomografisinde mesane lümeni posteriorunda $2 \times 2 \mathrm{~cm}$ 'lik bir taş izlendi (Şekil 1 ve 2). Taş nedenli üroloji konsültasyonu istendi.

Spinal anestezi altında üreterorenoskop ile girilerek mesane sol arka duvardaki 2,5 cm'lik taş pnömatik litotriptör ile kırılarak alındı. Taş içerisinde mesh'e ait olduğu düşünülen lifler gözlendi. Taş kırıldıktan sonra geride kalan mesh'e ait olduğu düşünülen yapılara bipolar rezeksiyon yapıldı. Bu cerrahi girişim sonrasında kontrol için yapılan ultrasonografide mesh lifleri 2 kez daha gözlendiği için tekrar Bowa arc 400 bipolar cihazı kullanılarak, 200 watt koagulasyon ile transüretral olarak bipolar rezeksiyon gerçekleştirildi. Mesane duvarına mesh ile iki taraflı oldukça girift yapışık bulunmasından dolayı, TVT tam olarak çıkartılmadı, mesane içerisine migrasyon yapan

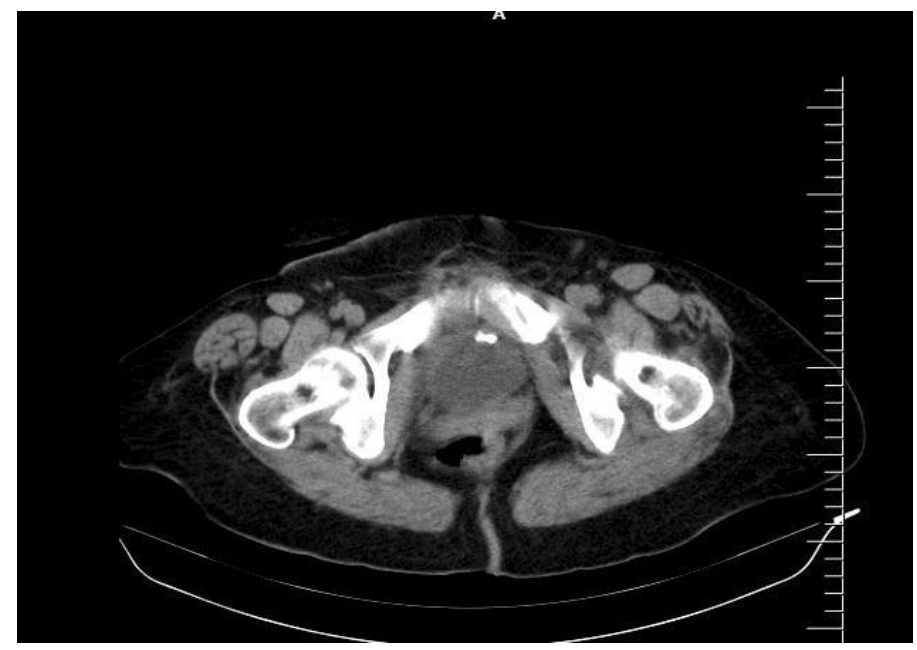

Şekil 1. Alt batın bilgisayarlı tomografisi transvers kesitte mesane lümeni posteriorunda taşla uyumlu hiperintens lezyon

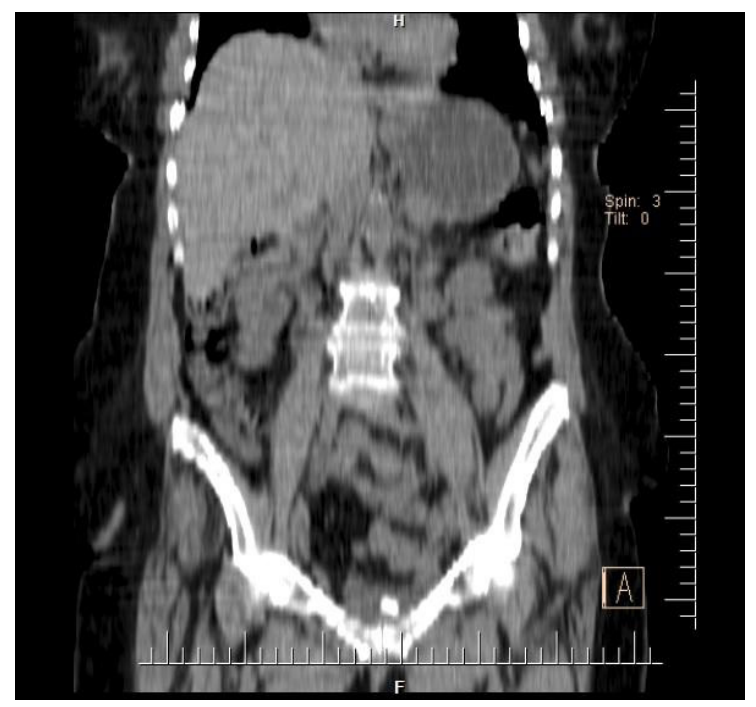

Şekil 2. Alt batın bilgisayarlı tomografisi koronal kesitte mesane lümeni içerisinde taşla uyumlu hiperintens lezyon

bölümü rezeksiyon ile çıkartıldı.

Hastaya 6 ay süre ile profilaktik antibiyotik (trimethoprim sulfometaksazol) tedavisi ve antikolinerjik tedavi önerildi. Pentosan sülfat, operasyon sırasında sistoskopide ülseratif lezyonların gözlenmesi ve intertisiyel sistit tanısı konulmuş olması nedeniyle 3 ay süre ile tedaviye ilave edildi. Postoperatif birinci aydan itibaren şikayetleri gerileyen hasta kontinan ve stabil olarak takibe devam ediyor.

\section{TARTIŞMA}

Çok yaygın uygulanan düşük morbiditeli, minimal invaziv bir yöntem olan TVT, stres inkontinans için uygulanan çok etkili bir operasyon olmasına rağmen mesane perforasyonu, hematom, idrar yolu enfeksiyonu, üriner retansiyon, disparüni gibi komplikasyonlar sıklıkla gelişebilmektedir $(4,5,7)$. Standart bir metod ile ve iyi bir eğitimden sonra uygulandığında komplikasyon oranları azalır.

Olgumuzda postoperatif geç dönemde başvuran hastanın sistit, dizüri, ağrı şikayetleri dikkate alınarak araştırılmış ve mesane taşı tespit edilmiştir. Mesane taşı gelişimi TVT operasyonunun nadir bir komplikasyonudur. Literatürde TVT sonrası mesane taşı gelişimi bildiren az sayıda olgu sunumu ve vaka serisi bulunmaktadır $(8,9)$. Bildirilen bu olguların tamamında taş içerisinde veya taşla birlikte sütür materyali ve/veya mesh'e ait parçalar da izlenmiştir $(8,9)$. Bizim vakamızda da taş içerisinde mesh'e ait olduğu düşünülen lifler gözlendi. 
Mesaneye TVT migrasyonuna bağlı gelişen mesane taşlarının tedavisinde çeşitli teknikler kullanılmaktadır. En yaygın olarak elektrorezeksiyon veya lazer gibi yöntemler ile taşın kırılarak endoskopik olarak çıkarılması uygulanmaktadır (9). Özdemir et al. (8) TVT sonrası mesane taşı gelişen bir olguyu tarif ettikleri çalışmalarında taşın çok büyük olması nedeniyle suprapubik sistostomi yöntemiyle çıkardıklarını bildirmişlerdir. Bizim olgumuzda taş pnömatik litotriptör ile kırılarak endoskopik olarak çıkarıldı. Girişim sonrasında kontrol ultrasonografisinde mesh lifleri tekrar gözlendiği için plazmakinetik (bipolar rezeksiyon) gerçekleştirildi.

Çoskun et al. (10) tarafından inkontinans cerrahisi ile birlikte POP rekonstrüriktif onarımının etkisi değerlendirilmiştir. Eş zamanlı yapılan POP rekonstrüktif cerrahisinin (anterior kolporafi, posterior kolporafi veya vajinal histerektomi) TVT ve TOT alt gruplarında MUS prosedür sonuçları üzerindeki etkisini değerlendirmesinde, kısa dönem sonuçları ve başarısı üzerne bir etki bulunmamıştır. Naidu et al. (11) eş zamanlı POP cerrahisi ile MUS'un tek başına MUS cerrahisi kadar güvenli ve etkili olduğunu belirtmişlerdir.

Geçirilmiş SUI cerrahisi olan hastalar sistit, dizüri ve ağrı şikayetleri ile başvurduğunda mutlaka mesane komplikasyonları hatırda tutulmalı ve hastalar sistoskopi ile değerlendirilmelidir. TVT sonrası gelişen mesane taşlarının tedavisinde uygun hastalarda endoskopik litotripsi etkin ve güvenli bir şekilde kullanılabilir. Taş kırıldıktan sonra geride kalan mesh yapılarına bipolar rezeksiyon yapılabilir.

Çıkar Çatışması: Çalışmada herhangi bir çıkar çatışması yoktur.

Finansal Çıkar Çatışması: Çalışmada herhangi bir finansal çıkar çatışması yoktur.

Yazışma Adresi: Jule Eriç Horasanlı, Necmettin Erbakan Üniversitesi Meram Tıp Fakultesi Kadın Hastalıkları ve Doğum, Anabilim Dalı, Konya, Türkiye

Tel:+90 5554793394 e-mail: juleesen@gmail.com

\section{KAYNAKLAR}

1. Abrams P, Cardozo L, Fall M, et al. The standardisation of terminology of lower urinary tract function: Report from the Standardisation Sub-committee of the International Continence Society. Am J Obstet Gynecol 2002;187:6-26.

2. Işıkoğlu M, Yalçın Ö, Günay $S$, et al. Türkiye'deki kadınlarda üriner ve anal inkontinansın prevalansı. 2000;1. İnternational Congress on the Menopause \& The 4. National Congress, Antalya.

3. Ulmsten $U$, Henriksson $L$, Johnson P, et al. An ambulatory surgical procedure under local anesthesia for treatment of female urinary incontinence. Int Urogynecol J Pelvic Floor Dysfunct 1996;7:81-5.

4. Morey AF, Medendorp AR, Noller MW, et al. Transobturator versus transabdominal mid urethral slings: A multi-institutional comparison of obstructive voiding complications. J Urol 175 2006;1014-7.

5. Rardin CR, Rosenblatt N, Kohli JR. Release of tension-free vaginal tape for the treatment of refractory postoperative voiding dysfuction. Obstet Gyneacol 2002;100:898-902.

6. Khanuengkitkong S, Lo TS, Dass AK. Delayed vaginal and urethral mesh exposure: 10 years after TVT surgery. Int Urogynecol J 2013;24(3):519-21.

7. Boustead GB. The tension-free vaginal tape for treating female stress urinary incontinence. BJU Int 2002;89:687-93.

8. Özdemir A, Çakır S, Sözen H, et al. Development of bladder stone after tension free vaginal tape procedure: A case report. Journal of the Turkish German Gynecological Association 2011;12(4):256-8.

9. Blewniewski M, Markowski M, Kliś R, et al. Cystolithiasis in women as a distant complication after minimal invasive treatment of stress urinary incontinence. Central European Journal of Urology 2014;67(3):277-81.

10. Çoşkun B, Aksakal OS, Çoskun B, et al. The impact of concurrent pelvic organ prolapse reconstructive surgery on midurethral sling procedure outcome. Ginekol Pol 2018 89(4):189-94

11. Naidu $M$, Thakar $R$, Sultan $A H$. Outcomes of minimally invasive suburethral slings with and without concomitant pelvic organ prolapse surgery. Int J Gynaecol Obstet 2014;127:(1):69-72. 